\title{
MUSEUMSFORSKNING SOM MUSEUMSUTVIKLING
}

Anders Johansen

I perioden mars - oktober 2000 er det ved Bergen Museum blitt avholdt et forskerkurs i museumsstudier. ${ }^{1}$ Gjennom tre todagers samlinger har femten faste kursdeltakere, sammen med en veiledergruppe på fem², møttes til foredrag fra inviterte forskere, og til diskusjoner om egne prosjektplaner. Kurset har, slik det het $i$ invitasjonen, tatt sikte på

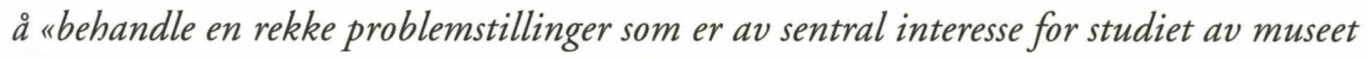
som medium og institusjon", for på den måten å "bidra til å opparbeide fagfeltet museologi i norsk sammenheng." Mer presist har hensikten vart "å inspirere til utvikling av ideer til museologiske forskningsprosjekter, og a bistå med veiledning fram mot ferdige prosjektbeskrivelser.»

I forlengelsen av denne kursvirksomheten er det nå i ferd med å utvikle seg et faglig miljø. For at miljøet skal holdes samlet, kommer det også i 2001 til å bli arrangert to seminarer. I tidsskriftet Nordisk Museologi vil det i tiden som kommer bli publisert en rekke tekster som først ble framlagt som foredrag her. Gjennom dem vil også andre kunne danne seg et inntrykk av aktiviteten i dette miljøet rundt Bergen Museum.

Initiativet til et forskerkurs for museumsansatte kom i sin tid fra Norsk Museumsutvikling. Når jeg svarte ja på forespørselen om å arrangere et slikt kurs, var det i første omgang på bakgrunn av rent lokale hensyn. Som styreleder for Bergen Museum så jeg for meg noen utfordringer som et slikt kurs kunne være en måte å ta fatt på.

ORGANISASJONSUTVIKLING, UNDERVISNING

Universitetsmuseet i Bergen er for tiden inne $\mathrm{i}$ en ganske tung omstillingsprosess. Av noen ganske spredte og sprikende enheter forsøker vi å bygge et enhetlig museum. A reformere organisasjonen er én del av denne integrasjonsprosessen. $\AA$ utvikle en rimelig enhetlig organisasjonskultur er en annen, og kanskje like nødvendig. De vitenskapelig ansatte har til nå identifisert seg med sine respektive disipliner. De er arkeologer, antroploger, zoologer, botanikere: Som fagpersoner hører de 
60 til på hvert sitt hold. Fra et ledelsessynspunkt har det derfor fortont seg som viktig å løfte fram de spørsmål som angår organisasjonen som helhet, altså de felles og spesifikt museale utfordringer. Når jeg var med på å invitere til et forskerkurs om "museet som medium og institusjon", var det for å begynne å rette oppmerksomheten mot emner som måtte være av felles interesse og som kunne forene de ulike faggruppene. Til nå har mange oppfattet seg som museumsfolk bare i den forstand at de, hver på sitt vis, gjør bruk av samlingene i sin forskning; jeg ønsket å bidra til å utvikle et museumsfaglig kunnskapsfelt som de alle sammen ville måtte inkludere $\mathrm{i}$ ideen om sitt faglige virke.

Dette var det ene lokale hensyn som tilsa satsing på museumsstudier. Det andre har sin bakgrunn i at Bergen Museum av universitetsledelsen er blitt pålagt å utvikle et tilbud i museumsutdanning. De initiativer som er kommet fra fagmiljøene har dels pekt mot undervisning $\mathrm{i}$ varianter av tradisjonelle fagtilbud, (bygningsvern, kulturlandskap), dels mot en type redskapsfag som består av praktiske kunnskaper til nytte for de etablerte virksomhetene, altså mot hva man gjerne kan kalle museografi. Selv har jeg ivret for at vi på sikt, og i samarbeid med andre miljøer ved universitetet, skal tilby en utdanning $\mathrm{i}$ museumskunnskap, forstått som museologi - ikke bare til folk som tar sikte på en karriere innen museumsfeltet, men også til framtidige kulturjournalister, kulturadministratorer og andre som på en eller annen måte vil få med feltet å gjøre.

Samtidig har det vært viktig for meg å understreke at all universitetsutdanning bør være forskningsbasert. Etter dette kriteriet har museet i dag kapasitet til å gi undervisning $i$ sentrale museografiske emner, men ikke i museologiske. For å begynne å opparbeide de faglige forutsetninger som bør ligge $i$ bunn for et slikt undervisningstilbud, så jeg det som viktig å ta initiativ til forskningsprosjekter, og til fora og nettverk der interessen for slik forskning kan utvikle seg.

Universitetet i Bergen ble i sin tid gjort oppmerksom på at «museene spiller en rolle i samfunnet, de integreres i undervisning og forskning, de har sosiale oppgaver og de nyttes som medier.» $\AA$ kunne tilby et fag som gir innsikt $\mathrm{i}$ disse forholdene, samt $\mathrm{i}$ «den teoretiske, filosofiske bakgrunn for museumsarbeidet", har "etablert seg som en nødvendighet", het det den gangen. ${ }^{3}$ Når dette nødvendige, etter nesten tretti år, ennå ikke har blitt noe av, skyldes det antakelig at museet stadig har ønsket seg et nytt undervisningstilbud - men uten å overveie behovet for først å framskaffe en ny type kunnskap. Museumskunnskap på universitetsnivå kan ikke være et rent teknisk og forvaltningsorientert redskapsfag, basert på de ansattes yrkeserfaring - men noe mer har verken dette eller andre norske museer til nå hatt å by på. Skal det gamle ønske kunne realiseres, må de museale praksiser selv gjøres til gjenstand for forskning. Det gjelder å begynne i rett ende: Først framskaffer vi vitenskapelig grunnlag - deretter kan det undervises.

Dette har vært min bakgrunn for å gå inn i dette arbeidet. I litt videre sammenheng kan en se behovet for museumsstudier slik:

\section{MUSEET SETT UTENFRA}

Alle andre medier, og alle andre kunnskaps- og kulturinstitusjoner av noen 
betydning, er tilknyttet en egen akademisk disiplin. Det finnes yrkesrettede utdanninger for mange av dem, men så finnes det i tillegg et universitetsfag: En litteraturvitenskap, en teatervitenskap, en kunsthistorie, en medievitenskap osv. I og med disse fagene er alle sentrale medier og kulturinstitusjoner gjenstand for forskning og forskningsbasert undervisning. For biblioteket er det en bibliotekshøyskole, for filmen en filmhøyskole osv., der slik aktivitet finner sted. Bare museet blir oversett. I så måte stiller det $\mathrm{i}$ klasse med flanellografen og rørposten og andre perifere medier. Dermed er museet langt på vei kommet til å mangle den type systematisk kunnskapsutvikling, og den type kritisk refleksjon og debatt omkring grunnlagsproblemer, som er så viktig for utviklingen innen disse andre mediesammenhengene. Dette er antakelig én grunn til at norske museer jevnt over ikke er så spennende som man burde kunnet forvente. Museet er så å si utelukkende blitt sett innenfra. Dermed har det egentlig vært usynlig. Museet selv - dets kunnskaps- og kommunikasjonsformer - blir nødvendigvis tatt for gitt, så lenge den faglige oppmerksomhet bare er rettet direkte inn mot innholdet i de ulike disipliner og mot de praktiske ferdigheter som skal til for å drive et museum. For at museet skal komme til syne for seg selv, er det nødvendig at det også blir sett utenfra, av andre - eller av ansatte som for en stund gis anledning til å opptre som andre og innta den utenforståendes posisjon.

Kunnskap om litteratur er ikke det samme som ferdigheter i å lage litteratur. For de fleste er dette helt opplagt: Litteraturvitenskap er ikke det samme som skrivekurs. Tekstanalyse, litteraturhistorie osv. har sin berettigelse, selv om resultatet ikke er dikt og romaner. Slik er det også i de utdanner ikke skuespillere, kunsthistorie ikke billedkunstnere, medievitenskap ikke reportere: Hva studentene lærer, er å analysere, vurdere og historisk perspektivere teaterets, maleriets og de moderne massemedienes former for kommunikasjon.

Allikevel er det ofte vanskelig å få museumsfolk til å gå med på, ja til i det hele å forstå, at det kan være mulig å anlegge et lignende blikk på deres egen virksomhet, for å gjøre den til studieobjekt - eller at noe slikt kan være fruktbart og i det lange løp nyttig. ${ }^{4}$ Dét indikerer i hvilken grad museet er blitt usynlig for dem, og dermed uproblematisk og egentlig udiskutabelt.

\section{OFFENTLIGHET}

Hvis en nå tenker strategisk på betydningen av å opparbeide et slikt felt, er det klart at det vil kunne stimulere til kreativitet og til kritisk refleksjon i museumsverdenen. Det vil også kunne berike den kunnskap som museene søker å formidle, med en rekke nye perspektiver. Men det er også grunn til å framheve at det i dag mangler en utviklet offentlighetssammenheng omkring museene. Den litterære institusjonen består ikke bare av forfattere, forleggere og lesere, men også av anmeldere, essayister, litteraturhistorikere, biografer. De skaper oppmerksomhet om litteraturen, forvalter et språk å behandle den i, reiser debatter, viser dens relevans. På den måten stimulerer de den skapende aktiviteten, og på den måten utdanner de et publikum. Men den litterære offentligheten, som altså forvalter kunnskap om og skaper interesse for litterære problemstil- 
62 linger, beror nettopp på litteraturstudiene ved universiteter og høyskoler, og i bunn og grunn på den forskning som utføres der.

De bildende kunster fungerer i en lignende sammenheng. Kunsthistoriefaget utdanner, direkte og indirekte, kritikere, debattanter, kurs- og foreningsledere, og muliggjør dermed en lang rekke aktiviteter som understøtter og utfyller kunstnernes og galleristenes virke. Som resultat av mediestudiene som ble dratt i gang fra omkring 1990, gjelder noe lignende nå også for film, fjernsyn og presse. Dét merkes på en stadig mer kvalifisert anmelderog debattvirksomhet og på en ny slags kritisk journalistikk rettet mot massemediene. Men museene har altså ingen slik plass i kulturoffentligheten. Alt annet anmeldes i pressen - diktsamlinger, konserter, til og med ballett - bare ikke museumsutstillinger.

A etablere museologi som fagfelt, dvs. i første omgang å skape et fagmiljø og dra i gang forskningsaktivitet, er altså et viktig grep, tror jeg - ikke bare for utviklingen av litt spesielle institusjoner som universitetsmuseene, men også for sektoren som helhet.

Helt generelt kan en si at det er viktig å stimulere til forskning ved museene. Det kan også være riktig å insistere på at museenes kunnskapsformidling så lang som råd bør ha bakgrunn i egen forskning. ${ }^{5}$ Men forskning om museet selv kan altså ha en spesiell strategisk betydning for utvikling av sektoren. Skal det først gjøres en særskilt satsning på forskning ved museene, tror jeg det vil være fornuftig å sette inn midlene her.

\section{TVERRFAGLIGHET}

Til forskerkurset i Bergen har vi, som foredragsholdere, invitert museumsforskere fra England, Nederland, Sverige. Fra de hjemlige miljøene har vi fătt bidrag fra historikere, filosofer, sosialantropologer, kunsthistorikere, medievitere. Bare noen av disse fagene er museumsfag. Slik vil det antakelig måtte være med utviklingen av dette feltet i det hele tatt: Det vil, også på sikt, måtte dreie seg om et temafag, som trekker på mange ulike typer ressurser fra samfunns- og kulturvitenskapene. Bare i liten grad forvaltes disse ressursene av de etablerte museumsfagene selv. $\mathrm{Vi}$ trenger perspektiver og metoder hentet fra tekstog diskursanalyse, fra retorikk og allmenn semiotikk, og fra idéhistorie, kunnskapssosiologi, osv. - i tillegg til det som museenes egne kunsthistorikere og etnologer kan bidra med.

For noen år siden var jeg med på å starte opp medievitenskap som universitetsfag. $\mathrm{Da}$ var det nødvendig å trekke på andre fagmiljøer enn bransjens egne, og på en annen slags innsikt enn den som forvaltes av dens profesjonsutdanninger. Det var nettopp ikke journalister, men litteraturvitere, historikere, sosiologer, antropologer som kom sammen om dette prosjektet. Noen av dem hadde praktisk medieerfaring, andre ikke. Men til sammen disponerte de over et bredt utvalg teoretiske og metodiske redskaper som kunne importeres fra de etablerte fag, tilpasses nye oppgaver, og settes inn $\mathrm{i}$ arbeidet med det sammensatte medie- og massekommunikasjonsfeltet.

Slik må vi antakelig også gå fram her. Museologi er "museum science», ifølge ICOMs definisjon, og skal ikke forveksles 
med slik yrkesfaglig kjennskap til «methods and practices in the operation of museums» som utgjør nabofeltet museografi. Som vitenskap kan den imidlertid vanskelig sies å være en disiplin på linje med sosialantropologi eller arkeologi, definert ved en egen grunnlagsproblematikk og en egen metodikk. Museologien må i stedet defineres ved sin gjenstand. Denne gjenstanden er det om å gjøre å få belyst $\mathrm{i}$ dens institusjonelle, epistemologiske, kommunikative osv. aspekter. Til slik allsidig belysning trengs det tilnærmings- og framgangsmåter som er blitt utviklet innen en mengde forskjellige samfunnsog kulturfag, og som mange av dem også er felles om å forvalte.

\section{MELLOM UNIVERSITET OG MUSEUM}

Museet er et mer nærliggende studieobjekt for en universitetsansatt sosiolog eller medieviter enn for museenes egne arkeologer og zoologer. Dette betyr antakelig at museumsforskningen ikke bare, og kanskje heller ikke primært, må ta sikte på rekruttering fra de museumsansattes egne rekker. Det utføres faktisk forskning av dette slaget i dag, blant hovedfagsstudenter og stipendiater i fag som historie, kunsthistorie, medievitenskap osv. Uten på noen måte å ha gjort systematiske undersøkelser, har jeg fått kjennskap til publikumsstudier $^{6}$, utstillingsanalyser ${ }^{7}$, studier av historiske utstillingsprosjekter ${ }^{8}$, av museers rolle i lokale endrings- og moderniseringsprosesser ${ }^{9}$, og av ny informasjonsog kommunikasjonsteknologi i utstillingsog annen formidlingssammenheng ${ }^{10}$. Noe av det viktigste en nå kan foreta seg, er trolig å oppmuntre til slik aktivitet, sørge for at noen slike hovedfagsinteresser kan videreføres i doktorgradssammenheng, og så samle og kanalisere denne aktiviteten inn mot museumsmiljøene. På sikt vil en slik kunne skape grunnlag for rekruttering til stillinger med forsknings- og undervisningsoppgaver i museumssektoren selv.

Samtidig er det klart at det ved museene er et ganske utbredt ønske om faglig påfyll og utvikling. Mange ansatte er både interessert i og kvalifisert til å arbeide med fagutvikling gjennom egne forskningsprosjekter. I noen tilfeller kan slik forskning ta form av et doktorgradsarbeid. Men det er klart at det her også er behov for midler til forskningsarbeider som kan ha et visst preg av utrednings- eller utviklingsarbeid, og som gjerne kan være av noe mindre omfang. Stipendier for et års eller et halvt års arbeid kan være tilstrekkelig til å produsere en rapport eller noen artikler som kan være av stor verdi, selv om de altså ikke er doktoravhandlinger. Slik aktivitet kan så tenkes knyttet opp mot mer ambisiøse forskningsprosjekter, gjennom et seminarprogram og lignende tiltak for å skape et faglig nettverk eller miljø.

Dette kan sikkert gjøres på mange måter. Mitt poeng er at det allerede finnes ressurser i universitets- og høyskolemiljøene, og at et program for museumsforskning ikke minst må ta sikte på å ta fatt $\mathrm{i}$ og nyttiggjøre seg dem.

Hvilke emner er det så en kan tenke seg å sette i gang forskning på? Jeg skal, ganske løst, antyde fire hovedområder: Museet kan studeres som kommunikasjonsform, som kunnskapsbetingelse, som kilde til kulturhistorie, som arena for politiske, ideologiske osv. samfunnsprosesser. 
MUSEET SOM

\section{KOMMUNIKASJONSFORM}

Det er et påtrengende behov for utdypet forståelse av museet i dagens informasjons- og kommunikasjonssituasjon, altså av de utfordringer dette gamle mediet står overfor i konkurransen med de nye. ${ }^{11}$ I denne sammenheng kunne en tenke seg utforskning av utstillingsspråket og dets muligheter: Enten semiotiske studier av bestemte utstillinger, sett som tekster som kan leses og fortolkes på ulike vis, eller studier av presentasjonsformenes retorikk og estetikk. Spesielt er det grunn til å legge vekt på at museene, med IT-teknologien, står overfor nye muligheter, både når det gjelder dokumentasjon og formidling. $\mathrm{Vi}$ trenger å få utforsket disse mulighetene, så vel med hensyn på deres praktisktekniske, som på deres kunnskapsteoretiske, pedagogiske, estetiske osv. aspekter.

Endelig tror jeg det er grunn til å framheve behovet for publikumsstudier. Vi trenger å vite mer om hvordan folk opplever og forstår museene, og om hva de bruker disse forståelsene til. I medievitenskapen har den kvalitative publikumsforskningen, og kanskje særlig den såkalte resepsjonsanalysen, i seinere tid gitt et bilde av overraskende variert og kreativ tilegnelse: Folk med ulike bakgrunn oppfatter tydeligvis medietekster ut fra egne interesser og forutforståelser, og bruker dem til egne formål i sine egne små verdener - og dét i en slik grad at den tradisjonelle senderbudskap-mottaker-modellen har begynt å gå i stykker for forskerne. Å bli oppmerksom på denne aktivt fortolkende omgang med teksten er å stille spørsmål ved tanken om påvirkning og om enkel overføring av informasjon, og å begynne å revi- dere sine oppfatninger av hva massekommunikasjon i det hele går ut på. Skal vi vinne innsikt $\mathrm{i}$ hvordan museenes kunnskaps- og verdiformidling i praksis finner sted, vil jeg tro det kan være nyttig å skaffe seg lignende overraskelser - gjennom åpne, fordypete samtaler og intervjuer, observerende deltakelse i undervisningsprosjekter, og lignende krevende, vitenskapelige metoder.

\section{MUSEET SOM VILKAR FOR KUNNSKAPSPRODUKSJON}

Kunnskapsutvikling er som kjent ikke en rent kumulativ prosess: Til tider skifter den spor, slik at nye sider av virkeligheten kommer til syne, og nye tanker blir mulig å tenke. Hva man regner som kunnskap beror ikke bare på hvilke framskritt som er gjort, men også på de grunnleggende paradigmer, diskurser osv. som angir framskrittets retning - og dertil på de praktiske og institusjonelle omstendigheter som kunnskapsproduksjonen i hvert tilfelle må tilpasse seg. For å komme til klarhet om museumskunnskapenes vilkår kan det være nyttig å betrakte dem som innvevd i mer omfattende kulturmønstre, og som historisk foranderlige sammen med dem. Like nyttig kan det imidlertid være å skille dem ut fra deres samtid, for å forsøke å få tak på deres særtrekk og deres særlige forutsetninger i museumsinstitusjonen selv.

Det er mye som tyder på at de ulike museumsfag har noe til felles, til og med på tvers av skillet mellom natur- og kulturfag - en innretning mot klassifikasjon og systematikk, for eksempel - som i en eller annen grad skiller dem fra den øvrige forskning innen hver disiplin, og som i siste omgang beror på samlingene som 
dokumentasjonsform. Slike forhold kan det være viktig å få et bevisst forhold til ikke bare for å opparbeide kritisk distanse til egen forskning og til egen kunnskapsutvikling i det hele, men også for at museumsvesenet skal sette seg i stand til å formulere hva som er dets særlige bidrag til den totale kunnskapsproduksjonen.

Nylig var jeg til stede ved en presentasjon av universitetsmuseene overfor bevilgende myndigheter. Innlederne framhevet at disse museene ikke bare formidler, men også framstiller, kunnskap. Dét er det imidlertid mange som gjør - forskningsstiftelser, universitetsinstitutter osv. Jeg er ikke sikker på at noen lot seg overbevise om det fornuftige i å satse enda mer penger på å la museene gjøre mer av det samme. Det som manglet i denne argumentasjonen, var et forsøk på å formulere den særlige type kunnskap som museene er mer eller mindre alene om å skape og forvalte, eller peke på de samfunnsbehov som de, og få eller ingen andre, dermed kan fylle. Uten begreper om særtrekk ved den museale kunnskapen står vi svakere, vil jeg tro, $\mathrm{i}$ å argumentere for at den har en berettiget plass i den samlete kunnskapsallmenningen.

\section{MUSEETS KULTURHISTORIE}

Museets historie kan belyses gjennom studier av fortidige samlings- og utstillingspraksiser, av de kunnskapsregimer som har orientert dem, av de omgivende politiske og ideologiske forhold som har virket til å forme museumskunnskapen opp gjennom tidene. Dette kan selvfølgelig gi viktige bidrag til museumsvesenets selvforståelse. $\AA$ se sin egen institusjon i historiens lys er å se den som foranderlig, og dermed kan- skje også som forunderlig. Relativiserende historiske eller komparative studier har ofte den virkning at det altfor velkjente blir påfallende; dermed inviterer de så å si til å ta et steg tilbake for å se på seg og sitt med utenforstående observatørblikk. Like viktig er det imidlertid at slike studier der en for eksempel ikke først og fremst interesserer seg for tingene som de var før de kom på museum, men om deres liv i en skiftende museal virkelighet - kan legge nye lag av betydning til samlingene, og berike det stoff vi mener de kan formidle.

Noen av de aller første gjenstander som kom til Bergen Museum stammer fra admiral d'Entrecasteaux' ekspedisjon til Sydhavet tidlig på 1790-tallet. Admiralen var blitt sendt av sted for å finne ut av et spørsmål som opptok revolusjonstidens Frankrike ganske mye, nemlig om det kunne være noe i ryktene om Den edle villmann og det gode liv i pakt med naturen. Han gjorde seg noen bitre erfaringer, ekspedisjonen gikk sørgelig i oppløsning. Men samlingen han hadde skaffet seg underveis, havnet hos guvernøren for den danske kolonien Trankebar, i India, og siden hos Christie, i Bergen.

Denne historien blir fortalt $i$ en bok om stillehavssamlingen vår, som vi nylig fikk utgitt: Knut Mikjel Rios «Oceania gjenoppdaget i Bergen". ${ }^{12}$ Her framgår det også hvordan resten av samlingen kom til, nemlig ved gaver fra norske sjømenn som fra tidlig på 1800-tallet tok del i hvalfangsten i Stillehavet, i transporten av tømmer til Australia, i handelen med kopra og guano på de mange små øyene. Det er noen kapitler av norsk sjøfartshistorie som er blitt gravet ut av denne samlingen. Det er også noen kapitler av historien om hvordan kunnskapene har forandret seg 
66 gjennom århundrene, sammen med våre oppfatninger av Norges plass i verden og vårt forhold til de eksotiske andre: Av denne studien framgår det hvordan gjenstandene er kommet til å bety vidt forskjellige ting, etter hvert som de har funnet sin plass i skiftende sosiale, mytiske og vitenskapelige kontekster.

Bergen Museum kan sies å representere norsk og europeisk kulturhistorie gjennom en lang periode. Rios bok gir eksempel på en type kunnskapsarkeologi som jeg tror det er mange rike, uutforskede kilder til i museets gamle samlinger. Slik arkeologi kan berike formidlingsarbeidet: Gjennom et prosjekt "Virtuelt museum» som vi nå har fătt NFR-støtte til, vil materiale fra denne boken nå bli integrert med bilder av våre etnografika, og med dokumentarfilmer og annet antropologisk kunnskapsstoff om Stillehavsregionen, og dermed tilføre vår planlagte nettpresentasjon en verdifull refleksiv dimensjon.

\section{MUSEETS SAMFUNNSROLLE}

Museet kan betraktes som en institusjon som er innviklet i diverse økonomiske, politiske og ideologiske samfunnsprosesser. Som turistattraksjoner, arbeidsplasser, mottakere av sponsormidler og donasjoner, inngår museene $\mathrm{i}$ forskjellige spill om $ø$ konomiske ressurser. Som møteplasser for lokalhistorikere, slektsgranskere, formidlere av tradisjonelle kunster og håndverk osv. inngår de i lokale integrasjonsog orienterings-bestrebelser. Som stiftet av bransjeorganisasjoner, drevet av entusiaster og veteraner, inngår de i diverse selvhevdingsprosjekter; forsåvidt som musealisering også er en form for verditilskriving, er det slett ikke bare i kunstmuseene at det kjempes om anerkjennelse og prestisje. Som opplysningsinstitusjoner har museene dessuten demokratiske forpliktelser: De rår over kunnskapsressurser folk må ha tilgang til for å kunne opptre som kvalifiserte deltakere $\mathrm{i}$ offentlig meningsutveksling og politiske beslutningsprosesser. Som kunnskapsformidlere og holdningsskapere utøver museene imidlertid også makt: Møtet med publikum kan ses som en arena for forhandlinger om autoritet, medvirkning, tilgjengelighet, representasjon; fra et eller annet klasse-, kjønns- eller etnisitets-standpunkt vil nær sagt enhver utforming av denne arenaen kunne bestrides som noe i retning av et overgrep.

Jeg skal ikke gå i detaljer med dette, bare peke ut én problemstilling som antakelig må bli ganske sentral $\mathrm{i}$ tiden som kommer. En type institusjoner som har vokst fram som del av det nasjonale identitetsprosjektet, ja som har hatt sin berettigelse først og fremst ved sitt bidrag til dét, befinner seg nå i en situasjon som begynner å ligne på en global landsby, der det enkelte sted også blir stadig mer kulturelt sammensatt. Det påtrengende spørsmål er så hva det vil si å ta denne nye situasjonen inn over seg - $\mathrm{i}$ alt fra kultur- og historieforståelse til utstillingsspråk og mediebruk til underliggende verdistandpunkt og publikumskontrakt eller samfunnsforpliktelse.

\section{TEORI OG PRAKSIS}

La meg legge til at jeg tror det kan være viktig, i mye av dette, å gi åpninger for praktisk orientert forskning, eller for utforskning gjennom nyskapende museumsarbeid. Det er ikke nødvendig at alle forskningsresultater publiseres $\mathrm{i}$ avhand- 
lings- eller artikkelform. Vårt medium er utstillingen; det er mulig, som i eksperimentell arkeologi, for eksempel, å utføre forskning som også er et konserveringseller formidlingsarbeid, og å publisere resultatene blant annet i form av en utstilling. Hvis vi har et begrep om museumsforskning som også gir rom for slik aktivitet, vil vi kunne hjelpe til med å orientere forskningen innen de enkelte vitenskapsdisiplinenene inn mot allment museale problemstillinger, og så å si utvikle den samlingsbaserte forskningens repertoar samtidig som vi trekker konserverings- og formidlings- og gjerne også IT-personale inn i forskningsarbeidet. Fra mitt synspunkt, i alle fall, forekommer det viktig å oppmuntre til tverrfaglige prosjekter av et slag som gir den tekniske og pedagogiske ekspertisen en nøkkelrolle $\mathrm{i}$ selve forskningsprosessen - ikke minst for at også de skal ha faglige utviklingsmuligheter og karrieremål à strekke seg etter, og for at også deres arbeidsområder skal kunne utvikles gjennom vitenskapeliggjøring.

Ofte kan dette være eneste veien å gå. Når det gjelder de IT-baserte dokumentasjons- og formidlingsformer, må forskningen ofte, i det minste langt på vei, ta form av et utviklingsarbeid som systematisk bearbeider sine problemer og erfaringer: Forskningens gjenstand foreligger ikke, den må nettopp produseres i løpet av forskningsprosessen. At den slags kombinasjoner av teori og praksis kan være fruktbare, har vi erfaring for ved Institutt for medievitenskap, der for eksempel avhandlinger skrevet på grunnlag av egen dokumentarfilmproduksjon - dvs. med utgangspunkt i problemer som viser seg i konkret form, under veis i det praktiske arbeid - ofte har vist seg å inneholde mer originale og nyanserte diskusjoner enn tradisjonelt akademiske undersøkelser.

\section{SUMMARY \\ Museum studies as museum development}

This text points to the strategic value of museological studies for the development of the museum sector. In Norway, the museum is the sole exception to the rule that a medium or a cultural institution of any importance be regarded as an academic field of study. Lacking the kind of systematic knowledge, critical reflection and discussion of basic premises which normally originate in independent outsider positions, Norwegian museums are consequently deprived of a vital stimulus. In the case of the university museums, the absence of attention to common, specifically museum related problems is seen as an obstacle to the development of coherent institutions out of the various scientific disciplines. In a wider perspective, museums are seen as being not fully established within the cultural public sphere. The enviable attention paid to other kinds of cultural products partly depends on university courses furnishing critics, reviewers and debaters with descriptive languages, analytical skills and evaluative standards. Without these courses, and without the research activity that makes them possible, even literature, painting, and film would miss the kind of qualified conversations that actually mediate between creative activity and the interests of a wider public. Hence the establishment of a museological field of research is seen as a precondition for comparable activities highlighting museum events, pointing out their more or less interesting problematics and their possible relevance to society.

Noting that museology is a field of study defined by its object, not a scientific discipline defined by its methods or basic theory, the author mentions relevant research currently being done in various university departments. As a first realistic step he 
68 then recommends the encouragement of such activities and their channelling into museum networks. He points out four main areas of study for future development: the museum may be studied as a form of communication, as a condition for the production of knowledge, as a source of cultural history and as a social institution. While insisting on the distinction between a practical museographical 'view from the inside' and a critical, properly museological 'view from the outside' the author in conclusion argues that valuable insights may be gained from projects combining these perspectives. As a way of encouraging the scientific orientation of their work, the museums' technical and pedagogical staff may be included in teams exploring new methods of conservation or communication, making the problems they actually meet into their object of study. In particular, the communicative possibilities of the new media seem to be manifestly accessible in this way, studying the object while producing it.

\section{NOTER}

1. Denne teksten ble framlagt som innledning til en samtale med Norsk museumsutviklings ledergruppe, 13.10.00. En versjon av teksten er utgitt av Norsk museumsutvikling i deres skriftserie som nr. $6: 2000$.

2. Veiledergruppen har hatt opphav i Institutt for medievitenskap og Institutt for kulturstudier og kunsthistorie ved Universitetet i Bergen, og har bestått av John Aage Gjestrum, Anders Johansen, Kari Gaarder Losnedahl, Ingmar Meland og Hans Jacob Ågotnes.

3. Robert Kloster: Innstilling fra komitéen til utredning av museenes stilling innen universitetsstrukturen. Bergen 1972, s. 20-21.

4. John Aage Gjestrum: Museology and research in a Norwegian perspective, i: Nordisk Museologi nr. 2, 1995.

5. St.m. 22, 1999-2000: Kjelder til kunnskap og opp- leving (kap. 6.6: "Forsking ved musea»).

6. Mette Chr. Christensen. Uten tittel. En studie av publikum ved Samtidskunstmuseet.

Hovedoppgave. Institutt for medievitenskap, Universitetet i Bergen 1994

7. Bodil Nyaas: Det dro en hurtigbàt fra Bjorgvin $i$ 1580 (?). En analyse av utstillingsspråk og historieformidling $i$ utstillingen "Langsomt ble landet vart eget». Hovedoppgave. Institutt for medievitenskap, Universitetet i Bergen 1995.

8. Brita Brenna: Disiplinerte drommer: verdensutstillinger $i$ London og Paris 1851-1867. Hovedoppgave. Universitetet i Oslo 1994.

9. Turid Markussen: Facts and Power. Reflections around a community museum in Shetland. Hovedoppgave. Institutt for sosialantropologi, Universitetet i Tromsø, 1997.

10. Jfr. Gunnar Liestøls CD-ROM- og nettpublikasjoner Kon-Tiki Interactive.(Oslo 1995: Gyldendal) og The Kon-Tiki Web Site (http://www.kon-tiki.no), samt hans avhandling til doktorgraden Essays in Rhetorics of Hypermedia Design. Oslo 2000: Det historiskfilosofiske fakultet, Universitet i Oslo.

11. Anders Johansen: Museet i dagens mediesituasjon, i: Nordisk Museologi nr. 1, 2000.

12. Knut Mikjel Rio: Oceania gjenoppdaget i Bergen. Reiser i Bergen Museums samlinger fra Stillehavet. Bergen 1999: Bergen Museums skrifter / Kultur, nr. 3.

Anders Johansen, sosialantropolog og medieforsker, er professor i medie- og kulturhistorie ved Universitetet $i$ Bergen.

Adr.: Institutt for medievitenskap, Universitetet $i$ Bergen, Fosswinckelsgate 6, N-5007 Bergen.

Fax: +47-55589149

e-mail: anders.johansen@media.uib.no 